\title{
Determination of Cyproheptadine Hydrochloride Drugs in Pure Form and In Their Pharmaceutical Preparation with Pyridinium Fluorochromate (PFC) Reagent
}

\author{
*Ajay Kumar Pandey, Dharmendra Dwivedi \\ Department of Chemistry, Pt. S.N.S. Govt. P.G.College, Shahdol, (Madhya Pradesh), India \\ Corresponding Author: Ajay Kumar Pandey
}

\begin{abstract}
In this paper simple and convenient visual titrimetric method have been described for the determination of Cyproheptadine hydrochloride $(\mathrm{CPH})$ i.e. an antihistamine drug in pure form and in its dosage forms with pyridinium fluoro chromate (PFC) reagent. The principle of this method involves the oxidation of Cyclohepten ring of the Cyproheptadine hydrochloride $(\mathrm{CPH})$ by a known excess of potassium iodate in sulphuric acid medium followed by iodometric titration in presence of reagent pyridinium fluoro chromate $(P F C)$. The reagent pyridinium fluoro chromate (PFC) used in this method is a versatile oxidizing agent of chromium (VI). The value of percentage error, coefficient of variation (CV) and standard deviation (SD) have been calculated for accuracy and precision of result.
\end{abstract}

Keywords: Antihistamine drugs, Cyproheptadine hydrochloride drugs, Pharmaceuticals, Pyridinium fluoro chromate (PFC), titration.

Date of Submission: 07-07-2017

Date of acceptance: 17-07-2017

\section{Introduction}

The selected drug Cyproheptadine hydrochloride $(\mathrm{CPH})$ is a sedating antihistamine drug and is chemically known as 4-(5Hdibenzo [a,d]-cyclohepten-5-ylidene)-1-methylpiperidine hydrochloride[1] having molecular formula $\mathrm{C}_{21} \mathrm{H}_{21} \mathrm{~N}$. $\mathrm{HCl}$ and structural formula is as follows:<smiles>CN1CCC(=C2c3ccccc3C=Cc3ccccc32)CC1</smiles>

Figure A. Chemical structure of Cyproheptadine hydrochloride (CPH)

Cyproheptadine hydrochloride ( $\mathrm{CPH})$ is an antihistaminic and antiserotonergic drug having a sedating action with serotonin-antagonist, antimuscarinic and calcium-channel blocking action in pancreatic islet cells and smooth muscle [2]. Engelhrdt et al.,[3] was the first to synthesised this drug Cyproheptadine hydrochloride $(\mathrm{CPH})$.This $\mathrm{CPH}$ is mainly used for treating symptoms of allergic reactions caused by seasonal allergies, food, blood or plasma. It is also used in allergy symptoms like runny nose, watery eyes, sneezing, hives, itching eyes/nose. $\mathrm{CPH}$ is also used as clinical and veterinary medicine.

The drug Cyproheptadine (CPH) has an atropine like action and therefore it should not be used in new born or premature infants, nursing mothers and also if patient have been affected by narrow-angle glaucoma, a peptic ulcer, an enlarged prostate or bladder, stomach or bowel blockage.

Non-aqueous titration by using perchloric acid as titrant has been described by United States Pharmacoepia [4] where crystal violet is used as indicator for the detection of end point. Whereas Indian Pharmacopeia [5] mentioned use of UV spectrophotometer for the assay determination of its tablet in $0.1 \mathrm{M} \mathrm{HCl}$ at $286 \mathrm{~nm}$.

The oxidising reagent used here for the determination of Cyproheptadine hydrochloride $(\mathrm{CPH})$ is Pyridinium fluoro chromate (PFC) which is chromoium (VI) based oxidising reagent. Many researchers in field of chemistry have been extensively used chromium based compound as an oxidizing agent for both preparative 
and for analytical purpose. Some well known common reagents based on $\mathrm{Cr}(\mathrm{VI})$ are $\mathrm{H}_{2} \mathrm{CrO}_{4}, \mathrm{~K}_{2} \mathrm{CrO}_{4}, \mathrm{~K}_{2} \mathrm{Cr}_{2} \mathrm{O}_{7}$ and $\mathrm{CrO}_{3}$. The reagents based on $\mathrm{Cr}(\mathrm{VI})$ are so powerful that these are well efficient in oxidizing alkenes and alkynes, breaking the carbon- carbon bond as in ozone. No any other reagent is as efficient as chromium (VI) reagent is effective for the partial oxidations of organic compound. Thus Chromium (VI) based reagents are well efficient in oxidizing the organic substrates. A variety of compounds containing chromium (VI) have proved to be versatile oxidizing reagents [6]. Extensive work has led to the development of a good number of these oxidants such as the Collins reagent[7], chromium trioxide-3,5-dimethylpyrazole complex[8], pyridinium chlorochromate (PCC)[9], pyridinium dichromate[10] 2,2'-bipyridinium chlorochromate[11], pyridinium fluorochromate( $\mathrm{PFC}$ [12,13], quinolinium fluorochromate[14], quinolinium chlorochromate[15], 3,5-dimethyl pyrazolium fluorochromate[16], 2,6-dicarboxypyridinium chlorochromate[17,18], N-methylpiperidinium chlorochromate[19], tetramethylammonium fluorochromate[20] and benzyltrimethylammonium fluorochromate[21]. This paper presents simple, accurate and precise visual titrimetric volumetric method for the determination of Cyproheptadine hydrochloride $(\mathrm{CPH})$ in pharmaceuticals. In this paper we have used Pyridinium fluoro chromate (PFC) as an oxidizing reagent due to its low cost, easy preparation, high solubility and yield, less toxicity and short reaction duration with the drug Cyproheptadine hydrochloride $(\mathrm{CPH})$.

\section{Materials And Methods}

2.1.Solution of Pyridinium Fluorochromate (0.03 N): Solution of PFC was prepared by dissolving $0.497 \mathrm{gm}$ of PFC in $150 \mathrm{ml}$ glacial acetic acid (MERCK) and made up the volume with distilled water in $250 \mathrm{ml}$ volumetric flask. The prepared solution was standardised iodometrically with standard Sodium thio sulphate solution using starch as an indicator.

2.2. Solution of Sodium thio sulphate $(0.01 \mathrm{~N})$ : Stock solution of sodium thio sulphate $(0.01 \mathrm{~N})$ was prepared by dissolving $3.16 \mathrm{gm}$ of sodium thio sulphate (Unhydrous) AR grade of HI MEDIA in distilled water of $1000 \mathrm{ml}$ volumetric flask and made up to the mark with distilled water. The stock solution prepared in this way was standardised by using $0.01 \mathrm{~N}$ potassium dichromate (Moly Chem) solution iodometrically by using starch as an indicator.

2.3. Solution of Potassium Dichromate (0.01 N): Stock solution of $\mathrm{K}_{2} \mathrm{Cr}_{2} \mathrm{O}_{7}$ was prepared by dissolving 0.245 gm of $\mathrm{K}_{2} \mathrm{Cr}_{2} \mathrm{O}_{7}$ (A.R Grade of Moly Chem) in distilled water of $500 \mathrm{ml}$ volumetric flask.

2.4. Potassium Iodide( $\mathbf{1 0 \%}$ ): $10 \% \mathrm{~W} / \mathrm{V}$ aqueous solution was prepared in distilled water. The Potassium iodide used for an experiment is of AR grade of RANKEM.

2.5. Starch Solution (1\%) : $1 \%$ of W/V aqueous solution of starch (LOBA Chemie) was prepared in boiling distilled water. The paste formed this way was filtered and kept to cool for some minutes. Always fresh starch solution has been prepared for accurate results.

2.6. Preparation of Sample Solution : Taken $100 \mathrm{mg}$ pure compound of Cyproheptadine hydrochloride (CPH) supplied on request, as gift sample by CIPLA Ltd, Mumbai in $100 \mathrm{ml}$ volumetric flask and dissolved it in $20 \mathrm{ml}$ of methyl alcohol (FISHER).The solution of volumetric flask has been shaken thoroughly for twenty minute so that compound may dissolve properly. After getting homogenous solution the flask was made upto the mark with distilled water.

2.7. Preparation of tablet Solution: Taken 20 Ciplactin- $4 \mathrm{mg}$ tablets (Manufactured by Cipla Ltd, Sigaddi, Kotdwar, Pauri Garhwal) has been obtained from local commercial source and these tablets were crushed to fine power. The powder equivalent to $100 \mathrm{mg}$ of sample, was taken in $100 \mathrm{ml}$ calibrated flask and dissolved in the same process as described above for the pure solution of $\mathrm{CPH}$.

2.8. Method: Aliquots of drug samples containing 1 to $5 \mathrm{mg}$ were taken in $100 \mathrm{ml}$ stoppered conical flask (Iodine flask) and to this $5 \mathrm{ml}$ of $0.03 \mathrm{~N}$ PFC reagent (Prepared in 60\% acetic acid) was added to it. Again $10 \mathrm{ml}$ of $5 \mathrm{~N}$ sulphuric acid was added to same reaction mixture of said flask. There after reaction mixture was shaken thoroughly, in order to mix the contents of flask properly and kept to stand the whole solution of flask for required reaction time at room temperature $\left(25-30^{\circ} \mathrm{C}\right)$ so that reaction between the contents of flask may be completed. After the completion of reaction $5 \mathrm{ml}$ of $10 \% \mathrm{KI}$ was added to same reaction mixture and whole reaction mixture was shaken properly and again allowed to stand for one minute. The unconsumed PFC was determined by iodometric titration by using starch as an indicator. Similarly blank experiment was also performed using all the regents under identical condition except the drug sample. The amount of PFC consumed for the given drug sample was calculated by the difference in the titre values of 
sodium thio sulphate solution for blank and actual experiment. The recovery of the drug sample was calculated with the amount of PFC consumed for the sample. Later on for accuracy and precision percentage error, coefficient of variation and standard deviation of each drug sample were calculated. Finally Standard Drug Addition method was also performed to evaluate the authenticity of the method.

2.9. Calculation: The expression used to determine the amount of drug present in the measured aliquot for each experiment is as follows:

Weight $(\mathrm{mg})$ of sample $=\frac{\mathrm{M} \mathrm{X} \mathrm{N}(\mathrm{B}-\mathrm{S})}{\mathrm{n}}$

Where,

$\mathrm{M}=$ Molecular weight of the sample.

$\mathrm{N}=$ Normality of sodium thiosulphate solution.

$\mathrm{B}=$ Volume of sodium thiosulphate solution for blank.

$\mathrm{S}=$ Volume of sodium thiosulphate solution for sample.

$\mathrm{n}=$ Stoichiometry of the reaction.

By using above mentioned process the determination of Cyproheptadine hydrochloride has been achieved for 1$5 \mathrm{mg}$ of pure sample of $\mathrm{CPH}$ and in its pharmaceutical preparation (i.e Ciplactin) but for convenience, the results as recorded in Table-1 have been shown only for 1,3 and $5 \mathrm{mg}$ of sample size.

\section{Figures \& Table}

3.1. Possible course of reaction: The Cyproheptadine hydrochloride $(\mathrm{CPH})$ or dibenzocycloheptene consists of an isosteric vinyl group (cyproheptadine) and the ring nitrogen has been replaced by a $\mathrm{sp}^{2}$ hybridised carbon atom. The oxidising reagent PFC oxidises the double bond at position 10,11 of cycloheptene to ketonic group and thus PFC with $\mathrm{CPH}$ establishes stoichiometric ratio of 1:1.On the basis of stoichiometric ratio established between PFC and pharmaceutical drug Cyproheptadine hydrochloride (CPH) and after the survey of different literature as mentioned above the proposed reaction may be expressed as:<smiles>CN1CCC(=C2c3ccccc3C=Cc3ccccc32)CC1</smiles>

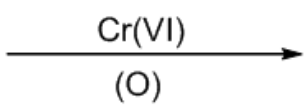<smiles>CN1CCC(=C2c3ccccc3CC(=O)c3ccccc32)CC1</smiles>

Table-1 Determination of Cyproheptadine hydrochloride (CPH) with 0.03N PFC

\begin{tabular}{|c|c|c|c|c|c|c|c|c|}
\hline \multirow[t]{2}{*}{$\begin{array}{l}\text { S. } \\
\text { No. }\end{array}$} & $\begin{array}{c}\text { Amount of } \\
\text { aliquots } \\
\text { taken }\end{array}$ & $\begin{array}{l}\text { Amount } \\
\text { Present }{ }^{\#}\end{array}$ & $\begin{array}{l}\text { Reactio } \\
\text { n time }\end{array}$ & \multirow[t]{2}{*}{ Molecularity } & $\begin{array}{l}\text { Amount obtained } \\
\text { by calculation } \#\end{array}$ & Error & SD & $\mathrm{CV}$ \\
\hline & (ml) & (mg) & $(\min )$ & & (mg) & $(\%)$ & (mg) & (mg) \\
\hline \multicolumn{9}{|c|}{ Analysis of Cyproheptadine hydrochloride (CPH) in Pure form } \\
\hline 1 & 1 & 0.998 & 10 & 1 & 0.989 & -0.90 & 0.0057 & 0.5763 \\
\hline 2 & 3 & 2.992 & 10 & 1 & 2.969 & -0.77 & 0.0038 & 0.1280 \\
\hline 3 & 5 & 4.986 & 10 & 1 & 4.957 & -0.58 & 0.0032 & 0.0646 \\
\hline \multicolumn{9}{|c|}{ Analysis of Ciplactin tablet (Manufactured by Cipla Ltd) } \\
\hline 1 & 1 & 0.993 & 10 & 1 & 0.985 & -0.81 & 0.0022 & 0.2234 \\
\hline 2 & 3 & 2.975 & 10 & 1 & 2.956 & -0.64 & 0.0027 & 0.0913 \\
\hline 3 & 5 & 4.930 & 10 & 1 & 4.915 & -0.31 & 0.0037 & 0.0753 \\
\hline
\end{tabular}

\# Mean value of three determinations has been done for each case. \# \# Value obtained is the average of nine determination.

\section{Conclusion}

The stoichiotric ratio between the PFC reagent and Cyproheptadine hydrochloride $(\mathrm{CPH})$ has been found to be 1:1.This ratio remains constant even under varying reaction conditions i.e. change in concentration of the reagent, reaction time, reaction medium etc.It has been also observed that $0.03 \mathrm{~N}$ concnetration of PFC and reaction duartion of 10 minute at room temperature is most appropriate condition for the determination of $\mathrm{CPH}$ drug.The effect of reaction medium has also been studied and observed that in absence of sulphuric acid 
the reaction proceed very slow and conentration of $5 \mathrm{~N}$ sulphuric acid gives accurate results.This visual volumetric titration method is simple,rapid, accurate and economically best in comprasion to other method where sophisticated instruments is required.The propesed method is convenient to be carried out at any laboratory.Thus proposed method is best for routine quality analysis of Cyproheptadine hydrochloride in pure form and in its pharmaceutical preparations for pharmaceutical companies manufacturing the $\mathrm{CPH}$ drug.

\section{Acknowledgements}

The authors thank Cipla India Ltd., Mumbai, India, for gifting pure Cyproheptadine hydrochloride.Authors are grateful to thank the authorities of the Pt. Sambhu Nath Shukla Government Post Graduate College, Shahdol (Madhya Pradesh) mainly to the Depatment of Chemistry for providing facililities for the completion of this experiment.

\section{References}

[1] S.C. Sweetman, Martindale- The Complete Drug Reference, Pharmaceutical Press,London, thirty-third ed., $2002,414$.

[2] X. Feas, L. Ye, P. Regal, C.A. Fente, A. Cepeda., J. Sep. Sci., 32,2009,1740.

[3] Engelhrdt et al J. Med. Chem, 8,1965, 829.

[4] "The United States Pharmacopoeia" XXIV Revision, the National Formulary XIX Rockville, USP Convention 2000.

[5] "The Indian Pharmacopoeia". Vol. I (The controller of Publications, Govt of India, Ministry of Health and Family Welfare, New Delhi), 1996, 218

[6] K.B.,Wiberg., Oxidations in Organic chemistry, Academic Press, New York, 1965

[7] J.C. Collins, W.W. Hess and J.F.Frank ., Dipyridine chromium (VI) oxide oxidation of alcohols in dichloromethane. Tetrahedron Lett. 30,1968,3363-3366.

[8] E.J. Corey and GWJ Fleet., Chromium trioxide-3,5- dimethylpyrazole complex as a reagent for oxidation of alcohols to carbonyl compounds. Tetrahedron Lett. 45,1973,4499- 4501.

[9] E.J. Corey and J.W. Suggs., Pyridinium chlorochromate: An efficient reagent for oxidation of primary and secondary alcohols to carbonyl compounds. Tetrahedron Lett. 31,1975,2647- 2650.

[10] E.J.Corey and G. Schmidt., Useful procedures for the oxidation of alcohols involving pyridinium dichromate in aprotic media. Tetrahedron Lett. 20,1979,399-402.

[11] F.S.Guzeic and F.A.Luzzio., The oxidation of alcohols using 2,2'-bipyridinium chlorochromate. Synthesis. 18,1980,691-696.

[12] M.N. Bhattacharjee, M.K.Chaudhuri and S.Purkayastha., Some aspects of pyridinium fluorochromate $\mathrm{C}_{5} \mathrm{H}_{5} \mathrm{NHCrO}_{3} \mathrm{~F}(\mathrm{PFC})$ oxidations. Tetrahedron. 43,1987,5389-5392.

[13] M.N. Bhattacharjee, M.K.Chaudhuri, H.S. Dasgupta and N.Roy., pyridinium fluorochromate: a new and efficient oxidant for organicsubstrates. Synthesis. 20,1982,588-590.

[14] V.Murugesan and A.Pandurangan., Quinolinium fluorochromate: a new reagent for the oxidation of organic compounds. Indian J Chem. 31B,1992,377-378.

[15] R.Srinivasan, C.V.Ramesh and W.K.Madhulatha., Oxidation of alcohols by quinolinium chlorochromate. Indian J Chem. 35B, 1996,480-481.

[16] U.Bora, M.K.Chaudhuri, D.Dey, D.Kalita, W.Kharmawphlang and G.C.Mandal.,3,5-Dimethylpyrazolium fluorochromate (VI) $\mathrm{C}_{5} \mathrm{H}_{8} \mathrm{~N}_{2} \mathrm{H}\left[\mathrm{CrO}_{3} \mathrm{~F}\right]$ (DmpzHFC): A convenient new reagent for oxidation of organic substrates. Teterhedron.,57,2001,2445- 2448.

[17] M.Tajbaksh, R.Hosseinzadeh and M.Yazdani-Niaki., Synthesis and application of 2,6- dicarboxypyridinium chlorochromate as a new oxidizing reagent for alcohols, silyl ethers and THF ethers under mild and nonaqueous conditions. J Chem Res.,2,2002,214- 217.

[18] R.Hosseinzadeh, M.Tajbaksh and M.Yazdani-Niaki., 2,6- Dicarboxypyridinium chlorochromate: A mild, efficient and selective reagent for oxidative deprotection of oximes to carbonyl compounds. Tetrahedron Lett. 43,2002,9413-9416.

[19] M.Tajbaksh, M.M.Heravi, F. Mohanazadeh,S. Sarabi and M.Ghassemzadeh., N- methylpiperidinium chlorochromate adsorbed on alumina: A new deoximation reagent. Monats Chem. 132,2001,1229-1231.

[20] A.R.Mahjoub, S.Ghammami and M.Z.Kassaee., Tetramethyl ammonium fluorochromate (VI): A new and efficient oxidant for organic substrates. Tetrahedron Lett. 44,2003,4555-4557.

[21] M.Z.Kassaee, M. Hattami M and L.Moradi., Benzyltrimethyl ammonium fluorochromate (VI): A novel, efficient and selective oxidant Acta Chim Slov. 51,2004,743-750.

IOSR Journal of Applied Chemistry (IOSR-JAC) is UGC approved Journal with Sl. No. 4031, Journal no. 44190.

Ajay Kumar Pandey. "Determination of Cyproheptadine Hydrochloride Drugs in Pure Form and In Their Pharmaceutical Preparation with Pyridinium Fluorochromate (PFC) Reagent." IOSR Journal of Applied Chemistry (IOSR-JAC) 10.7 (2017): 01-04. 